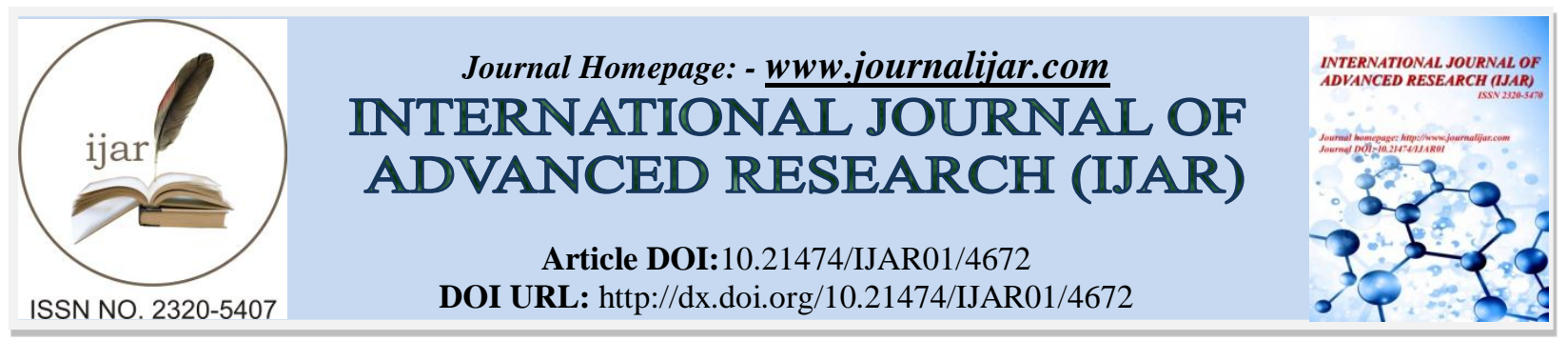

RESEARCH ARTICLE

\title{
CLINICAL BEHAVIOUR OF METASTATIC TRIPLE NEGATIVE BREAST CARCINOMA: AN
} INSTITUTIONAL REVIEW.

\section{Abhash Shankar ${ }^{1}$, PuneetNagpal ${ }^{1}$, Budhi Singh Yadav ${ }^{1}$, DivyaDahiya ${ }^{2}$, Rajinder $\operatorname{Singh}^{2}$ and Sushmita Ghoshal'.}

1. Department Of Radiotherapy, Pgimer Chandigarh.

2. Department Of General Surgery, Pgimer Chandigarh.

\section{Manuscript Info}

Manuscript History

Received: 24 April 2017 Final

Accepted: 29 May 2017

Published: June 2017

Key words:-

Triple negative, younger, aggressive, worse prognosis, high recurrence

\section{Abstract}

Introduction - Triple Negative Breast Cancer (TNBC) is a type of breast cancer which is characterized by its unique molecular profile of ER, PR and HER2Neu Negativity. They are generally aggressive in nature, present with different metastatic patterns and there are no targeted therapies till date. It constitutes $15-20 \%$ of all breast carcinomas. To identify the clinical behaviour of TNBC, we evaluated the 62 patients of TNBC presenting in our department in last 3 years.

Methods:- Patients diagnosed with breast carcinoma (tissue diagnosis) presenting to our institution were evaluated for their ER, PR and HER2Neu status. Triple Negative (ER Negative, PR Negative, HER2Neu Negative) breast cancer subtype patients were given treatment according to the stage and patient preferences. Operable patients willing for mastectomy were operated followed by adjuvant treatment while inoperable patients were given Neo-adjuvant chemotherapy followed by surgery $+/$ - radiotherapy.

Results:-Median age of patients was 45 years (range 28-81). Majority of patients were locally advanced $(82.3 \%)$ and $79 \%$ had positive nodes at the time of presentation. Initial metastasis in the cohort was around $24.2 \%$ despite most tumours being locally advanced. Bone and Liver was the most common site of metastasis at diagnosis. Upfront surgery was done in $35.48 \%$ patients while $64.52 \%$ patients were started on chemotherapy out of which $62.5 \%$ patients were amenable to surgery. At a median follow up of 23 months local recurrence was seen in $9.7 \%$ and distant metastasis in $40.32 \%$ of cases. Most common site of distant metastasis was Brain (14.52\%) followed by Liver (11.29\%) and Lung (11. 29\%).The median disease free survival (DFS) and time to local failure in the study was 11 and 12.5 months respectively.

Conclusion:-TNBCs present in younger women show variable response to chemotherapy and carry the worse prognosis, having high recurrence rate. 


\section{Introduction:-}

Breast cancer is the most common cancer in women [1]. It has been divided into various subtypes depending upon oestrogen receptor (ER), progesterone receptor (PR) and HER2/neu status. ER-positive comprises about $70 \%$ of cases while ER-negative breast cancer constitutes approximately 40\% [2,3,4]. HER2/neu oncogene is amplified in about $15-20 \%$ of breast cancer cases [2]. Triple negative breast cancer (TNBC) is a type of breast cancer that does not express any of the markers and accounts for about $10-15 \%$ of all cases.

TNBC in general are aggressive in nature as compared to other subtypes [5].Histologically TNBC comprises of cells having high proliferation rate, are generally poorly differentiated, and, in most cases harbour mutations in the TP53gene $[6,7,8]$.

The aim of the present study is to evaluate the clinical characteristics and outcomes of patients with metastatic triple negative breast cancer treated at our institute in last three years.

\section{Materials and Methods:- \\ Patient selection:-}

Total 62 female patients diagnosed with breast carcinoma (tissue diagnosis) presenting to our institution between 20011-14 were evaluated for their ER, PR and HER2NEU status. Triple Negative (ER Negative, PR Negative, HER2neu Negative) breast cancer subtype patients (metastatic at presentation or having distant metastasis later on) were analyzed in this study.

\section{Pretreatment Evaluation:-}

Diagnosis of all cases was based on biopsy specimens. Staging was based on physical examination, USG whole abdomen, Chest radiograph and bone scan.

\section{Management:-}

All patients were managed by multimodality treatment, which includes chemotherapy, radiation therapy and surgery.

\section{Chemotherapy:-}

Chemotherapy consisted of 6 cycles of FAC chemotherapy, [F =5 FLOURO URACIL 600mg/m2 bolus injection (day 1) $+\mathrm{A}=$ doxorubicin $50 \mathrm{mg} / \mathrm{m} 2$ in a 1-hour infusion (day 1) $+\mathrm{C}=$ cyclophosphamide $600 \mathrm{mg} / \mathrm{m} 2 \mathrm{as} \mathrm{bolus}$ injection (day 1) ] either in the neo-adjuvant or adjuvant setting. Cycles were administered at 3-week intervals. Paclitaxel[175mg/m2] for 4 cycles was added after 4 cycles of FAC depending upon patients affordability Evaluation of response to chemotherapy was performed either by physical examination or imaging, after the induction chemotherapy.

\section{Surgery:-}

Surgery in the form of Breast conserving surgery(BCS) or radical like total mastectomy(TMAC) depending upon the patient's preference or tumor status was planned as a primary treatment in some patients or after induction chemotherapy depending upon the response.

\section{Radiation:-}

For patient who underwent TMAC radiation dose of $35 \mathrm{~Gy} / 40 \mathrm{~Gy}$ in 15 fractions was given to chest wall and supraclavicular area respectively. The dose to patients undergoing BCS was 40Gy/40Gy in 16 fractions to whole breast and supraclavicular area respectively followed by boost to tumor bed of 10Gy in 5 fractions.

For patients with metastatic disease at presentation, 6 cycles of palliative chemotherapy with either FAC alone or 4 cycles of FAC followed by 4 cycles of paclitaxel were planned. Local radiotherapy was given with radical or palliative intent depending upon response to chemotherapy.

After treatment, patients were followed by physical check-ups. Additional studies, including if necessary biopsy, were performed when indicated. Outpatients were followed every 3 months for 2 years and then twice a year. 


\section{Statistical Analysis:-}

In this retrospective study, frequency tables with counts and percentages were used to describe pre-treatment and treatment characteristics of the patients. Disease free survival (DFS) and Local control rates (LC) were calculated by the Kaplan-Meier method using statistical software SPSS for windows (version 19.0).

\section{Results:-}

Patient Profile And Treatment Details:-

Table 1 shows the patient profile and treatment given. The median age of presentation is 45 years(range $28-81$ years) $.37 .1 \%$ of the patients were $<40$ years of age while $62.9 \%$ were $>40$ years of age. $51.6 \%$ of the tumors were right sided with most common involved quadrant being the upper outer(41.9\%)

$82.3 \%$ of the patients had T3-4 tumors. $79 \%$ of the patients had nodal positivity.15 patients(24.2\%) had metastatic disease at presentation with most common site of metastasis being bone(40\%) followed by liver(20\%).

Upfront surgery was possible in 22(35.48\%) patients while 40 patients required upfront chemotherapy after which surgery was possible in 25 patients $(62.5 \%)$. Among the 47 patients who underwent surgery TMAC was done in 45 cases while BCS was done in only 2 patients.

\section{Response to Treatment:-}

Out of 25 patients who underwent neoadjuvant chemotherapy followed by surgery 3 patients had complete pathological response (12\%).

\section{Pattern of failure (Table 2):-}

At median follow up period of 23 months, out of 62 patients, 34 (54.8\%) patients failed the treatment. Majority of the failures (25 out of 34 ), were distant (40.32\%). 3 patients (4.8\%) had both local and distant failure, and 6(9.7\%) failed locally. The most common site of distant failure was Brain (14.52\%), followed by liver(11.29\%) and lung $(11.29 \%)$.

\section{Local Control rates (Figure 1):-}

The 1 year, 2 year and 5 year local control rates were $91.3 \%, 73 \%$ and $37 \%$ respectively. The median time to local failure was 12.5 months.

\section{Disease free survival (Figure 2):-}

The 1 year, 2 year and 5 year disease free survival were $84.9 \%, 72.3 \%$ and $13.5 \%$ respectively. The median time to any failure was 11 months.

\section{Discussion:-}

The term "TRIPLE NEGATIVE" specifies histologically proven ER/PR/Her2neu negativity [10,11,12].TNBC are more commonly present in younger, premenopausal as compared to old age (24\% versus $15 \%)[13,14]$.In this study, the median age of presentation is 45 years(range $28-81$ years). $37.1 \%$ of the patients were $<40$ years of age while $62.9 \%$ were $>40$ years of age.

TNBC comprising of $13-25 \%$ of breast cancers have a highly aggressive nature than other breast cancer subtypes accounting for a large number of metastatic disease. In our study $82.3 \%$ of the patients had T3-4 tumors.79\% of the patients had nodal positivity. $24.2 \%$ had metastatic disease at presentation with most common site of metastasis being bone $(40 \%)$ followed by liver $(20 \%)$.

Chemotherapy is the standard treatment for TNBC. It is very sensitive to cytotoxic therapy despite its aggressive nature. After treatment with chemotherapy approximately 30-45\% of patients achieve complete pathological response $[15,16]$. In this study $12 \%$ patients who underwent neoadjuvant chemotherapy followed by surgery had complete pathological response.

As reported in two studies done on TN breast cancer $6 \%$ of patients with early stage breast cancer had brain metastasis [17, 18, 19]. TNBC and HER2-positive breast cancers were associated with high rates of local recurrence in comparison to other groups as shown in a meta-analysis of studies comparing breast cancer subtype and loco 
regional recurrence [20].Patients with TNBC have a poor prognosis as compared to luminal subtypes and this difference was most common in the first 2 years after diagnosis[21].This is in comparison with the present study which shows at median follow up period of 23 months, out of 62 patients, $34(54.8 \%)$ patients failed the treatment. Majority of the failures (25 out of 34), were distant (40.32\%). 3 patients (4.8\%) had both local and distant failure, and 6(9.7\%) failed locally. The most common site of distant failure was Brain (14.52\%), followed by liver(11.29\%) and lung (11.29\%).

The 1 year, 2 year and 5 year local control rates were $91.3 \%, 73 \%$ and $37 \%$ respectively. The median time to local failure was 12.5 months. The 1 year, 2 year and 5 year disease free survival were $84.9 \%, 72.3 \%$ and $13.5 \%$ respectively. The median time to any failure was 11 months. This is consistent with findings from the previous studies which shows that the chances of developing metastases is more common in the first 2 years after diagnosis with a decline after the fifth year $[22,23,24,25]$.

\section{Conclusion:-}

Molecular subtyping of breast cancer is commonly done now a day as it helps in predicting the tumor behaviour and guiding further treatment. TNBCs present in younger women show variable response to chemotherapy and carry the worse prognosis. There are high chances of developing CNS metastases, especially in the first 5 years of diagnosis.

Table 1:- Patient profile and treatment characteristics.

\begin{tabular}{|c|c|}
\hline Characteristics & Number of patients (percentage) \\
\hline $\begin{array}{c}\text { Gender } \\
\text { Male } \\
\text { Female }\end{array}$ & $\begin{array}{c}0(0 \%) \\
62(100 \%)\end{array}$ \\
\hline $\begin{array}{l}\text { Age(years) } \\
\text { Median } \\
\text { Range } \\
<40 \\
>40\end{array}$ & $\begin{array}{c}45 \\
28-81 \\
23(37.1 \%) \\
39(62.9 \%)\end{array}$ \\
\hline $\begin{array}{c}\text { Tumor Site } \\
\text { LEFT } \\
\text { RIGHT } \\
\text { B/L } \\
\end{array}$ & $\begin{array}{c}29(46.8 \%) \\
32(51.6 \%) \\
1(1.6 \%)\end{array}$ \\
\hline $\begin{array}{c}\text { Tumor Quadrant } \\
\text { UPPER OUTER } \\
\text { UPPER INNER } \\
\text { CENTRAL } \\
\text { LOWER OUTER } \\
\text { LOWER INNER }\end{array}$ & $\begin{array}{c}26(41.9 \%) \\
5(8.1 \%) \\
17(27.4 \%) \\
12(19.4 \%) \\
2(3.2 \%)\end{array}$ \\
\hline $\begin{array}{c}\text { T SIZE } \\
\text { T1-2 } \\
\text { T3-4 }\end{array}$ & $\begin{array}{l}11(17.7 \%) \\
51(82.3 \%)\end{array}$ \\
\hline $\begin{array}{c}\text { NODE } \\
\text { N0 } \\
\text { N1 } \\
\text { N2 } \\
\text { N3 }\end{array}$ & $\begin{array}{c}13(21 \%) \\
27(43.5 \%) \\
16(25.8 \%) \\
6(9.7 \%)\end{array}$ \\
\hline $\begin{array}{c}\text { Metastasis } \\
\text { M0 } \\
\text { M1 }\end{array}$ & $\begin{array}{l}47(75.8 \%) \\
15(24.2 \%)\end{array}$ \\
\hline $\begin{array}{c}\text { Treatment } \\
\text { Sx ---> ADJUVANT } \\
\text { NEO ADJ-->Sx } \\
\text { CCT } \\
\end{array}$ & $\begin{array}{l}22(35.48 \%) \\
25(40.32 \%) \\
15(24.19 \%) \\
\end{array}$ \\
\hline $\begin{array}{c}\text { Sx type } \\
\text { TMAC } \\
\text { BCS }\end{array}$ & $\begin{array}{c}45(95.75 \%) \\
2(4.25 \%)\end{array}$ \\
\hline
\end{tabular}


Table 2:- Pattern of failure.

\begin{tabular}{|c|c|}
\hline Failure type & Number of failures (percentage) \\
\hline Total & $34(54.8 \%)$ \\
\hline $\begin{array}{c}\text { Local } \\
\text { Distant } \\
\text { Both }\end{array}$ & $\begin{array}{c}6(9.7 \%) \\
25(40.3 \%) \\
3(4.8 \%)\end{array}$ \\
\hline $\begin{array}{l}\text { Distant Failure- } \\
\qquad \begin{array}{l}\text { Bone } \\
\text { Brain } \\
\text { Liver } \\
\text { Lung } \\
\text { Cervical node }\end{array}\end{array}$ & $\begin{array}{c}3(4.84 \%) \\
9(14.52 \%) \\
7(11.29 \%) \\
7(11.29 \%) \\
2(3.23 \%)\end{array}$ \\
\hline
\end{tabular}

Figure 1:- Pattern of local control.

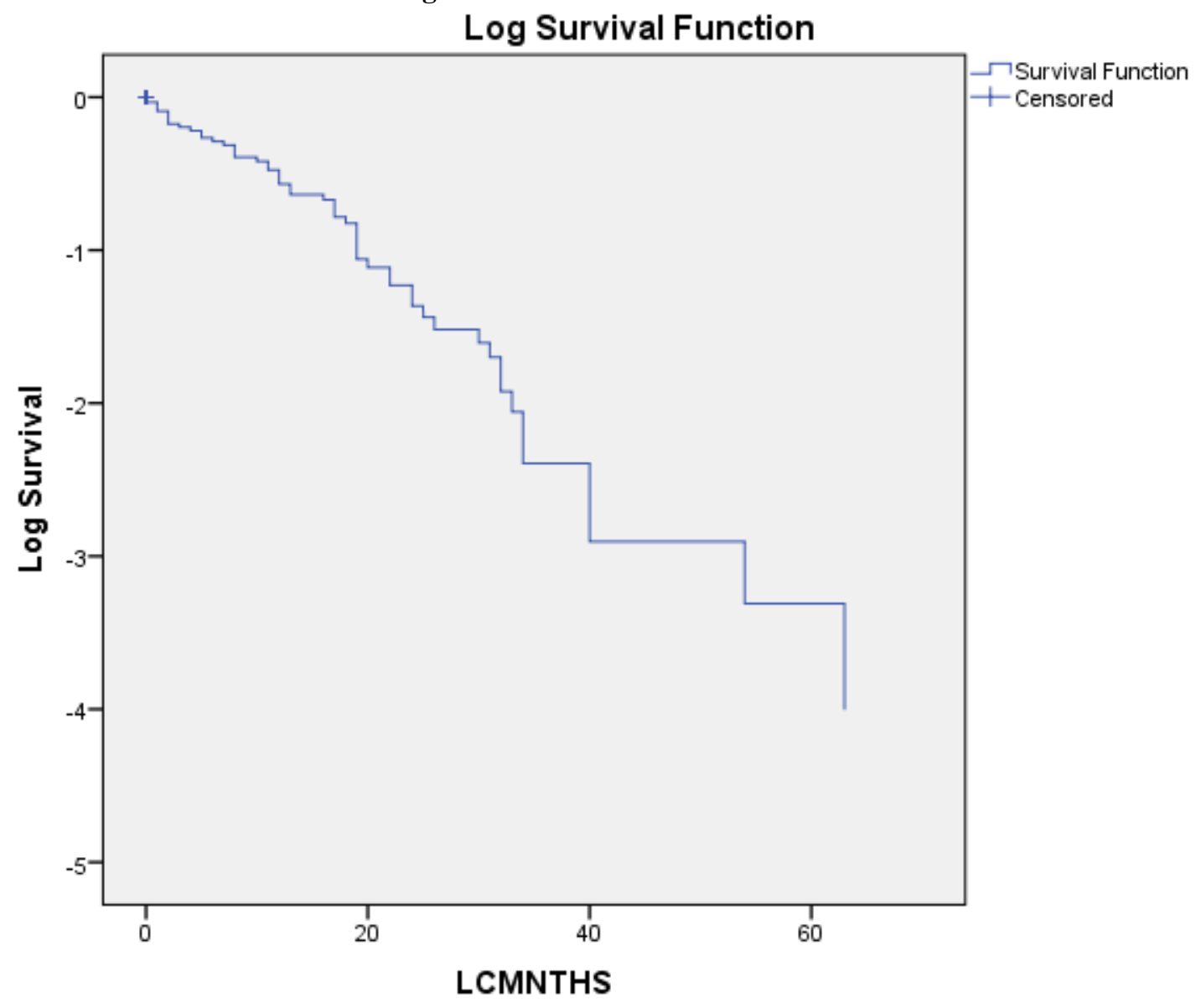


Figure 2:- Pattern of distal failure.

Log Survival Function

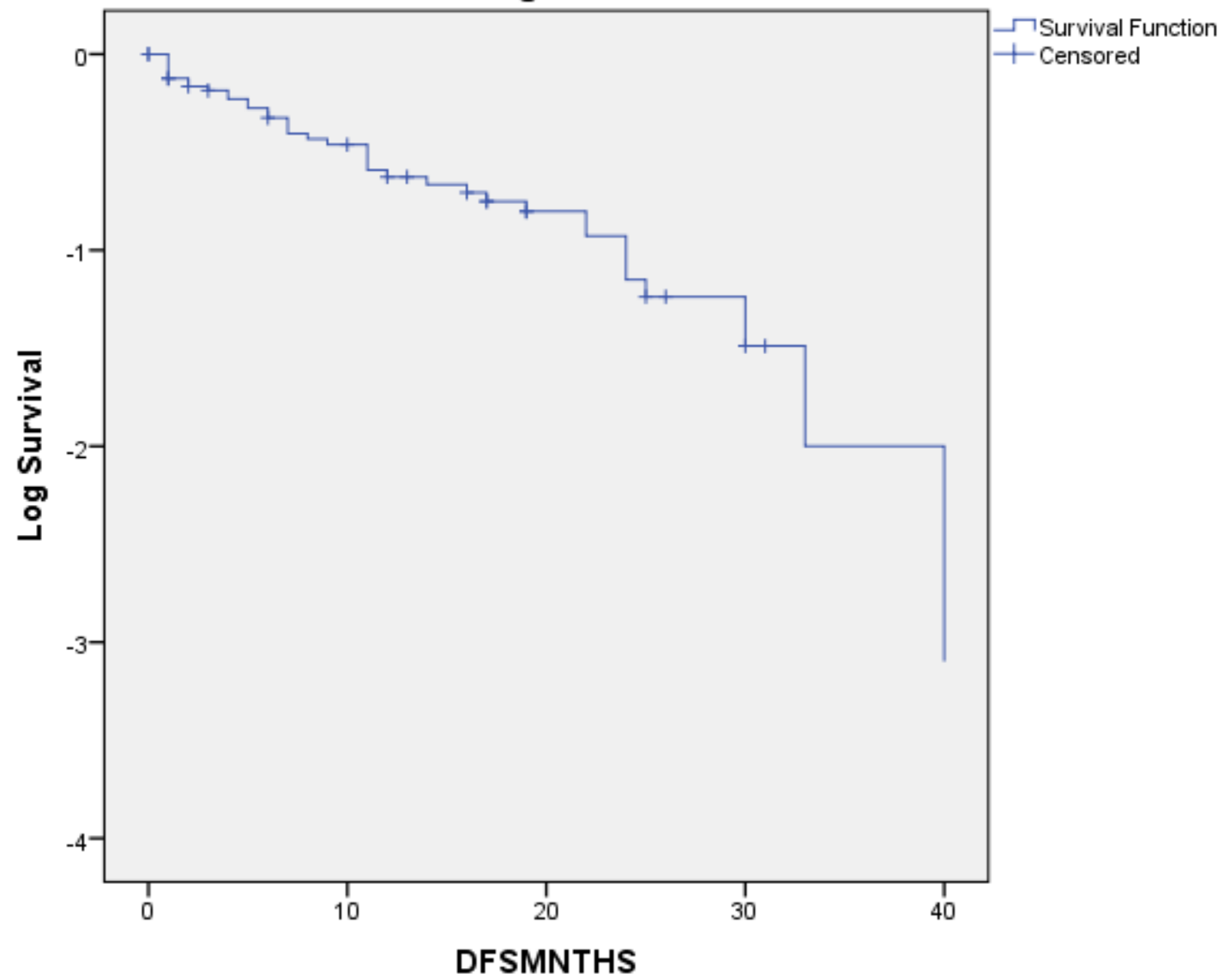

\section{References:-}

1. Perou CM, Sørlie T, Eisen MB, van de Rijn M, Jeffrey SS, Rees CA, et al. Molecular portraits of human breast tumours. Nature 2000;406:747-52.

2. Schiff R, Osborne CK, Fuqua SAWF. Clinical aspects of estrogen and progesterone receptors. In: Harris JR, Lippman ME, Morrow M, Osborne K, eds. Diseases of the Breast, 4th edn. Philadelphia, USA: Lippincott Williams and Wilkins, 2010: 408-42.

3. Bauer KR, Brown M, Cress RD, Parise CA, Caggiano V. Descriptive analysis of estrogen receptor (ER)negative, progesterone receptor (PR)-negative, and HER2-negative invasive breast cancer, the so-called triplenegative phenotype: a population-based study from the California cancer Registry. Cancer 2007; 109: 1721-28.

4. Stratton MR, Breast Cancer Linkage Consortium. Pathology of familial breast cancer: diff erences between breast cancers in carriers of BRCA1 or BRCA2 mutations and sporadic cases. Lancet 1997; 349: 1505-10.

5. Sorlie T, Perou CM, Tibshirani R, et al. Gene expression patterns of breast carcinomas distinguish tumor subclasses with clinical implications. ProcNatlAcadSci USA 2001; 98: 10869-74.

6. Perou CM, Sorlie T, Eisen MB, et al. Molecular portraits of human breast tumours. Nature 2000; 406: 747-52.

7. Thompson PA, Brewster AM, Kim-Anh D, et al. Selective genomic copy number imbalances and probability of recurrence in earlystage breast cancer. PLoS One 2011; 6: e23543.

8. Cancer Genome Atlas Network. Comprehensive molecular portraits of human breast tumours. Nature 2012; 490: 61-70.

9. Eisenhauer EA, Therasse P, Bogaerts J, Schwartz LH, Sargent D, Ford R et al.New response evaluation criteria in solid tumours: Revised RECIST guideline (version 1.1) Euro Jour Can.2009;45:228-47.

10. Robbins SL, Kumar V, Cotran RS. Robbins and Cotran pathologic basis of disease. 8th ed. Philadelphia, PA: Saunders; 2010.

11. Anders CK, Carey LA. Biology, metastatic patterns, and treatment of patients with triple-negative breast cancer. Clin Breast Cancer 2009;9(Suppl. 2):S73e81. 
12. Turner NC, Reis-Filho JS. Tackling the diversity of triple negative breast cancer. Clin Cancer Res 2013;19:6380e8.

13. O'Brien KM, Cole SR, Tse CK, et al. Intrinsic breast tumor subtypes, race, and long-term survival in the Carolina Breast Cancer Study. Clin Cancer Res 2010;16:6100e10.

14. Sorlie T, Tibshirani R, Parker J, et al. Repeated observation of breast tumor subtypes in independent gene expression data sets. ProcNatlAcadSci USA 2003;100:8418e23.

15. vonMinckwitz G, Untch M, Blohmer JU, et al. Definition and impact of pathologic complete response on prognosis after neoadjuvant chemotherapy in various intrinsic breast cancer subtypes. J ClinOncol 2012; 30: 1796-804.

16. Masuda H, Baggerly KA, Wang Y, et al. Diff erential response to neoadjuvant chemotherapy among 7 triplenegative breast cancer molecular subtypes. Clin Cancer Res 2013; 19: 5533-40.

17. Lin NU, Bellon JR, Winer EP: CNS metastases in breast cancer. J ClinOncol 22:3608-3617, 2004

18. Miller KD, Weathers T, Haney LG, et al: Occult central nervous system involvement in patients with metastatic breast cancer: Prevalence, predictive factors and impact on overall survival. Ann Oncol 14: 1072-1077, 2003

19. Dawood S, Broglio K, Esteva FJ, et al: Survival among women with triple receptor-negative breast cancer and brain metastases. Ann Oncol 20:621-627, 2009

20. Lowery AJ, Kell MR, Glynn RW, et al. Locoregional recurrence after breast cancer surgery: a systematic review by receptor phenotype. Breast Cancer Res Treat 2012;133:831e41.

21. Lin NU, Claus E, Sohl J, et al. Sites of distant recurrence and clinical outcomes in patients with metastatic triple-negative breast cancer: high incidence of central nervous system metastases. Cancer 2008;113:2638e45.

22. Dent R, Trudeau M, Pritchard KI, et al. Triple-negative breast cancer: clinical features and patterns of recurrence. Clin Cancer Res 2007;13:4429e34.

23. Colzani E, Johansson AL, Liljegren A, et al. Time-dependent risk of developing distant metastasis in breast cancer patients according to treatment, age and tumour characteristics. Br J Cancer 2014;110:1378e84

24. Dent R, Hanna WM, Trudeau M, et al. Time to disease recurrence in basal-type breast cancers: effects of tumor size and lymph node status. Cancer 2009;115:4917e23.

25. Dent R, Hanna WM, Trudeau M, et al. Pattern of metastatic spread in triple-negative breast cancer. Breast Cancer Res Treat 2009;115:423e8 